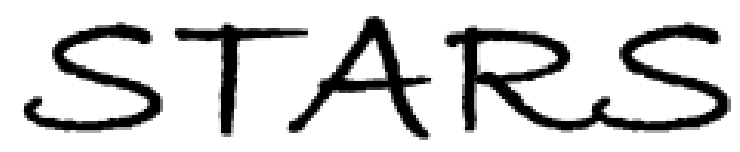

University of Central Florida

STARS

$1-1-2014$

\title{
On electronic structure of polymer-derived amorphous silicon carbide ceramics
}

Kewei Wang

Xuqin Li

Baisheng Ma

Yiguang Wang

Ligong Zhang

See next page for additional authors

Find similar works at: https://stars.library.ucf.edu/facultybib2010

University of Central Florida Libraries http://library.ucf.edu

This Article is brought to you for free and open access by the Faculty Bibliography at STARS. It has been accepted for inclusion in Faculty Bibliography 2010 s by an authorized administrator of STARS. For more information, please contactSTARS@ucf.edu.

\section{Recommended Citation}

Wang, Kewei; Li, Xuqin; Ma, Baisheng; Wang, Yiguang; Zhang, Ligong; and An, Linan, "On electronic structure of polymer-derived amorphous silicon carbide ceramics" (2014). Faculty Bibliography 2010 s. 6245.

https://stars.library.ucf.edu/facultybib2010/6245

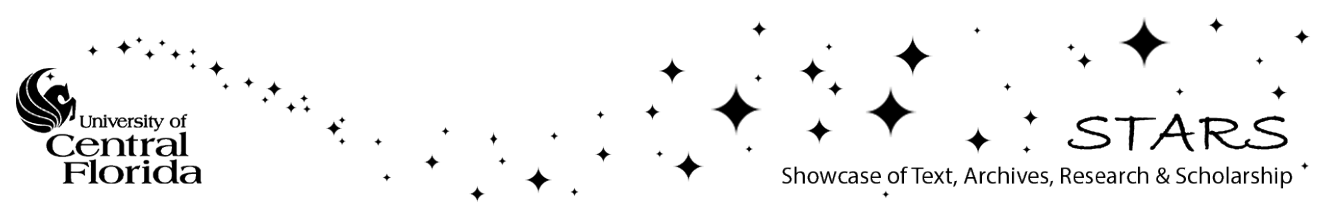




\section{Authors}

Kewei Wang, Xuqin Li, Baisheng Ma, Yiguang Wang, Ligong Zhang, and Linan An 


\section{On electronic structure of polymer-derived amorphous silicon carbide ceramics}

Cite as: Appl. Phys. Lett. 104, 221902 (2014); https://doi.org/10.1063/1.4881139

Submitted: 22 April 2014 . Accepted: 21 May 2014 . Published Online: 02 June 2014

Kewei Wang, Xuqin Li, Baisheng Ma, Yiguang Wang, Ligong Zhang, and Linan An
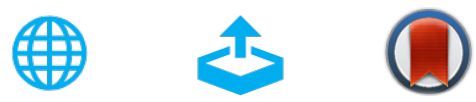

View Online

Export Citation

CrossMark

\section{ARTICLES YOU MAY BE INTERESTED IN}

On electric conduction of amorphous silicon carbonitride derived from a polymeric precursor Applied Physics Letters 102, 231902 (2013); https://doi.org/10.1063/1.4809825

Wireless passive polymer-derived SiCN ceramic sensor with integrated resonator/antenna Applied Physics Letters 103, 163505 (2013); https://doi.org/10.1063/1.4824827

Silicoboron-carbonitride ceramics: A class of high-temperature, dopable electronic materials Applied Physics Letters 78, 3076 (2001); https://doi.org/10.1063/1.1370540

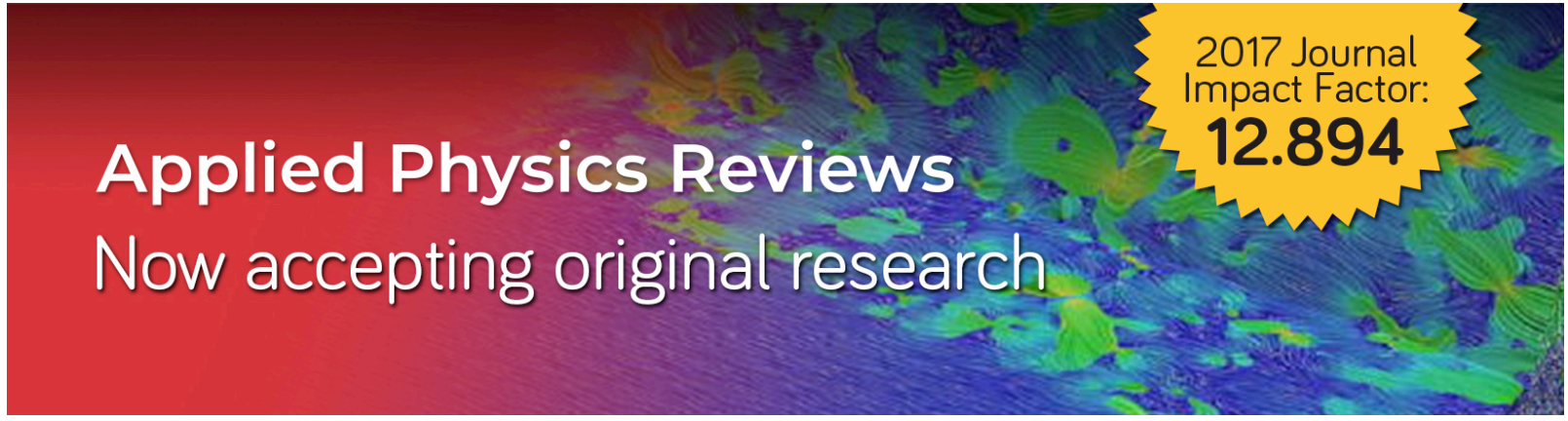




\title{
On electronic structure of polymer-derived amorphous silicon carbide ceramics
}

\author{
Kewei Wang, ${ }^{1,2}$ Xuqin Li, ${ }^{1,2}$ Baisheng Ma, ${ }^{1,2}$ Yiguang Wang, ${ }^{1,2, a)}$ Ligong Zhang, ${ }^{3}$ \\ and Linan $\mathrm{An}^{4, \mathrm{a})}$ \\ ${ }^{1}$ State Key Laboratory of Solidification Processing, School of Materials Science and Engineering, Science \\ and Technology on Thermostructural Composite Materials Laboratory, Northwestern Polytechnical \\ University, Xi' an, Shaanxi 710072, People's Republic of China \\ ${ }^{2}$ Science and Technology on Thermostructural Composite Materials Laboratory, Northwestern Polytechnical \\ University, Xi' an, Shaanxi 710072, People's Republic of China \\ ${ }^{3}$ State Key Laboratory of Luminescence and Applications, Changchun Institute of Optics, Fine Mechanics \\ and Physics, Chinese Academy of Sciences, Changchun, People's Republic of China \\ ${ }^{4}$ Department of Materials Science and Engineering, Advanced Materials Processing and Analysis Center, \\ University of Central Florida, Orlando, Florida 32816, USA
}

(Received 22 April 2014; accepted 21 May 2014; published online 2 June 2014)

\begin{abstract}
The electronic structure of polymer-derived amorphous silicon carbide ceramics was studied by combining measurements of temperature-dependent conductivity and optical absorption. By comparing the experimental results to theoretical models, electronic structure was constructed for a carbon-rich amorphous silicon carbide, which revealed several unique features, such as deep defect energy level, wide band-tail band, and overlap between the band-tail band and defect level. These unique features were discussed in terms of the microstructure of the material and used to explain the electric behavior. (C) 2014 AIP Publishing LLC. [http://dx.doi.org/10.1063/1.4881139]
\end{abstract}

Electric properties of polymer-derived ceramics (PDCs) have attracted tremendous interests due to their potential applications in high-temperature microelectromechanical systems and harsh environmental micro-sensors. ${ }^{1-4}$ Previous studies revealed that this class of materials exhibited a set of unusual electric properties as compared to conventional polycrystalline ceramics, including well-behaved high-temperature semiconducting behavior up to $1300^{\circ} \mathrm{C}, 5,6$ anomalously high piezoresistivity, ${ }^{7}$ and profound doping effect. ${ }^{8,9}$ It is believed that these properties are related to the unique structure of PDCs, which consists of disordered graphite nanoclusters and a heterogeneous silicon-containing amorphous matrix..$^{10}$ The conduction of PDCs is determined by the concentration and/or morphology of the free-carbon phase which has higher conductivity than the amorphous Si-phase. For the materials with the free-carbon phase forming a percolation network, the conduction is similar to that of glassy carbon. ${ }^{11}$ On the other hand, for the materials with the freecarbon phase not forming the percolation network, there are two conduction mechanisms: ${ }^{12}$ tunneling-percolation mechanism when the free-carbon content is higher than a threshold; or semiconducting mechanism controlled by the Si-phase when the free-carbon concentration is lower than the threshold. Despite these extensive efforts, the electronic structure of PDCs has received little attention, partially because that the amorphous nature of the materials makes it difficult for theoretically determining the electronic structures. Here, we report a study on experimental determination of the electronic structure of a polymer-derived carbon-rich amorphous silicon carbide $(a-\mathrm{SiC})$ by combining the measurements of temperature-dependent conductivity and optical absorption.

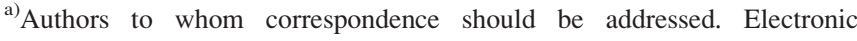
addresses: wangyiguang@mail.nwpu.edn.cn and linan.an@ucf.edu
}

The obtained electronic structure is then discussed in terms of its structure.

The amorphous silicon carbide studied here was synthesized using a polycarbosilane (PCS) as the precursor. The detailed synthesis procedure was reported in Ref. 13. In brief, the as-received PCS was first cross-linked at $400{ }^{\circ} \mathrm{C}$ in ultrahigh purity argon. The cross-linked product was then ground to powder of $1 \mu \mathrm{m}$ using high-energy ball milling. The powder was compressed into disk samples and pyrolyzed at $1000^{\circ} \mathrm{C}$ for $3 \mathrm{~h}$. Such obtained ceramics is amorphous with apparent chemical formula $\mathrm{SiC}_{1.45} \mathrm{O}_{0.08}{ }^{13}$ It is seen that the carbon content in the material is much higher than that required to form stoichiometric silicon carbide, indicating the existence of free carbon. Previous study suggested that the conduction of the current in the material is through free carbon and Si-phase in series instead of through any of them solely, ${ }^{13}$ indicating the material should be a matrix-controlled semiconductor.

For measuring the temperature-dependent conductivity of the material, the surfaces of the obtained specimen of $16 \mathrm{~mm}$ in diameter and $1 \mathrm{~mm}$ in thickness was first polished to $1 \mu \mathrm{m}$ finish. Silver paste was then painted on the surfaces of the sample as the electrodes. The conductivity of the material was obtained by measuring the I-V curve on Agilent $4155 \mathrm{C}$ semiconductor parameter analyzer in the temperature range of $50-650^{\circ} \mathrm{C}$. Fig. 1 plots the electrical conductivity of the material as a function of measuring temperature in Arrhenius format. It is seen that the conductivity significantly increased with increasing the measuring temperature in a nonlinear manner, indicating that the material is an amorphous semiconductor.

It is well-known that the temperature-dependent conductivity of amorphous semiconductors can be described by the following equation: ${ }^{14}$ 


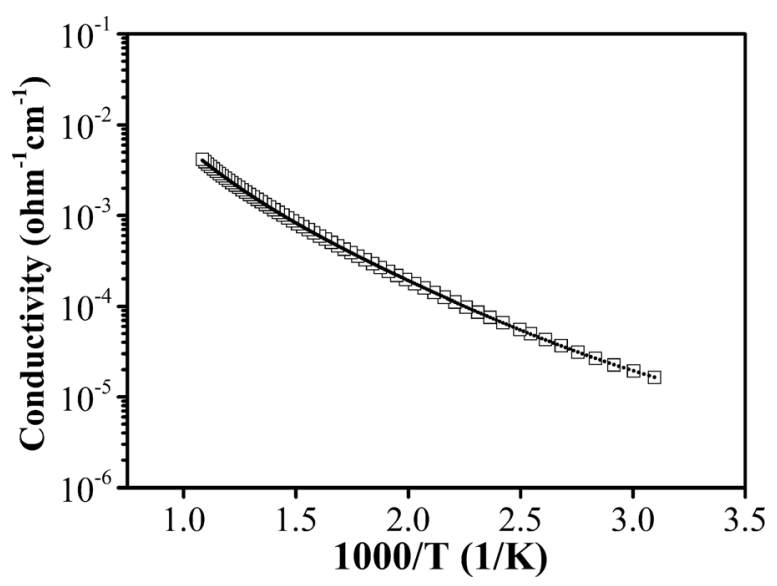

FIG. 1. The electrical conductivity of the material as a function of measuring temperature. The open square is the experimental data (data points were reduced to show the fitting curve); and the solid dotted line is computed from Eq. (1).

$$
\sigma=\sigma_{1} e^{-\frac{E_{C}-E_{F}}{k T}}+\sigma_{2} e^{-\frac{E_{A}-E_{F}+w}{k T}}+\sigma_{3} e^{-\left(\frac{T_{o}}{T}\right)^{1 / 4}}
$$

where $E_{C}, E_{A}$, and $E_{F}$ are the mobility edge of conduction band, the band tail, and the Fermi level, respectively; $w$ is the thermal activation energy, which is equal to the phonon energy of the material (neglecting the multi-phonon processes); $\sigma_{1}, \sigma_{2}$, and $\sigma_{3}$ are prefactors without clear physical meaning; and $T_{0}$ is a characteristic temperature. The first term is the contribution from the conduction in extended states, which occurs at the high-temperature range; the second term is the contribution from the conduction in band tail states, which exists in the middle temperature range; and the third term is the contribution from the conduction in localized states, which arises in the low-temperature regime. The experimental data are then fitted by Eq. (1) (Fig. 1). It is seen that the experimental data can be well fitted by the equation, suggesting the conduction of the material indeed follows the amorphous semiconducting model over the entire testing temperature range. The parameters determined by curve fitting are summarized in Table I. The gap between the band-tail band and Fermi energy $\left(E_{A}-E_{F}\right)$ and that between the conduction band and Fermi energy $\left(E_{C}-E_{F}\right)$ are then determined from the data to be 0.14 and $0.56 \mathrm{eV}$, respectively, by assuming that the phonon energy of the amorphous phase should be in the same range as that of its crystalline counterpart, which is about $100 \mathrm{meV}$ for $\mathrm{SiC} .^{15,16}$ The width of the band-tail band $\left(E_{C}-E_{A}\right)$ is also estimated to be $0.42 \mathrm{eV}$.

More electronic structural parameters were determined by optical absorption measurement. In order to avoid variation from sample to sample, the optical absorption was measured by using the same sample for conductivity measurement. After conductivity measurement, the electrodes on the surfaces of the sample were removed by polishing. The sample was then grinded to powder of $\sim 1 \mu \mathrm{m}$. The obtained

TABLE I. Fitting parameters for conductivity and optical absorption curves.

\begin{tabular}{lcccc}
\hline \hline$E_{C}-E_{F}(\mathrm{eV})$ & $E_{A}-E_{F}+w(\mathrm{eV})$ & $E_{g}(\mathrm{eV})$ & $E_{T}(\mathrm{eV})$ & $n$ \\
\hline 0.56 & 0.24 & 3.25 & 0.49 & 1.502 \\
\hline \hline
\end{tabular}

$a$-SiC powder was mixed with $\mathrm{KBr}$ powder and pressed into a disc of $10 \mathrm{~mm}$ diameter and $0.5 \mathrm{~mm}$ thick. The optical absorption spectrum of the mixture was obtained using a UV-3101 double channel spectrometer. The absorption spectrum of the $a$-SiC was then obtained by extracting the spectrum of the pure $\mathrm{KBr}$ powder from that of the mixture. The resultant absorption coefficient ( $\alpha$ ) of the $a-\mathrm{SiC}$ as a function of photon energy $(h v)$ is shown in Fig. 2(a). It is seen that unlike crystalline $\mathrm{SiC}$ which showed clear absorption edge, the $a$-SiC exhibited absorption over entire phonon energy range between 1.5 and $5 \mathrm{eV}$, a typical behavior of amorphous semiconductors.
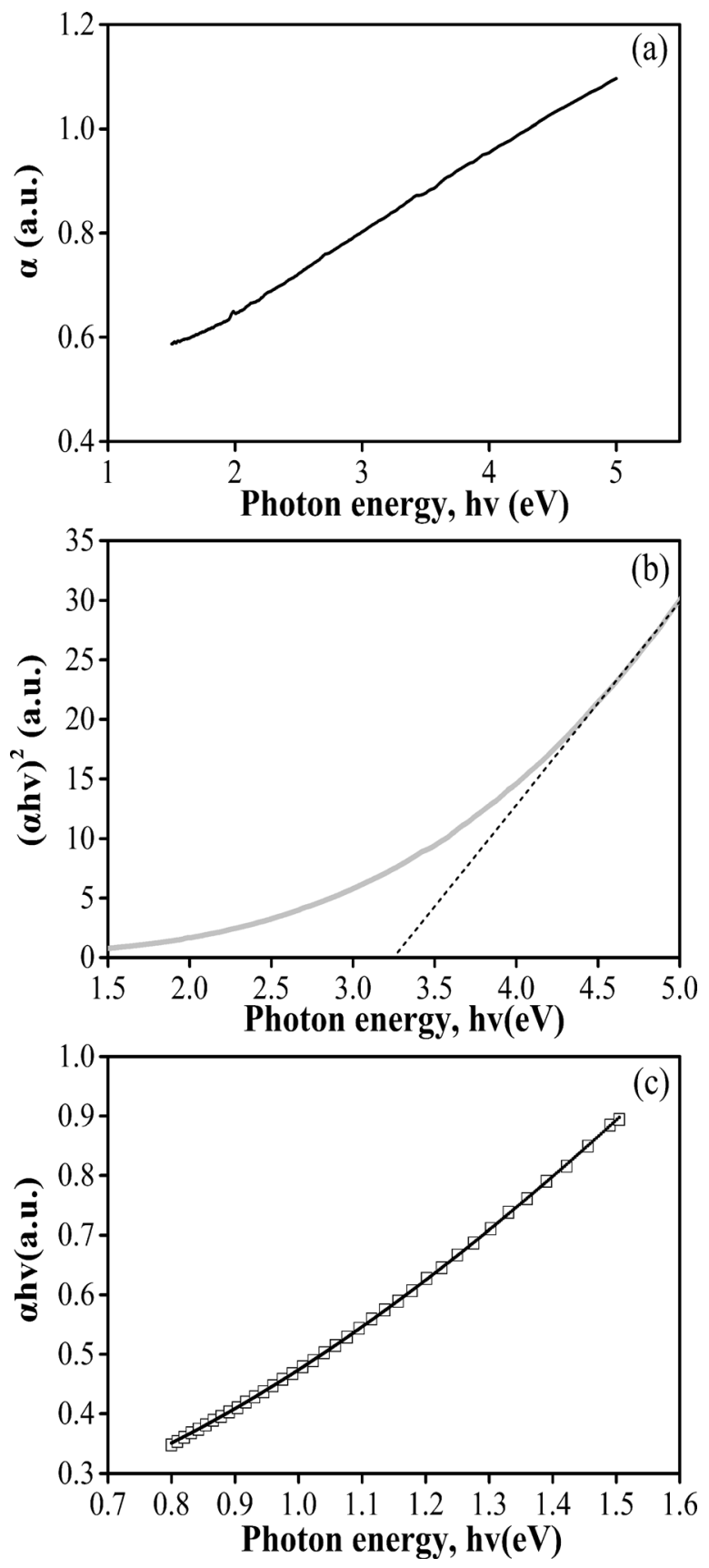

FIG. 2. (a) The resultant absorption coefficient $(\alpha)$ of the $a$-SiC as a function of photon energy ( $h v)$; (b) plot of $(\alpha h v)^{2}$ as a function of phonon energy, the band gap for the $a-\mathrm{SiC}$ is estimated by extrapolation (dashed lines); (c) plot of $\alpha h v$ as a function of the photon energy, the solid line is computed from Eq. (3). 
In order to obtain the electronic structure, the original spectrum was analyzed using theoretical models. It is suggested that amorphous semiconductors should exhibit a vertical optical transition between the two extended bands. ${ }^{17}$ This absorption can produce an absorption edge according to the following equation:

$$
(\alpha h v)^{2} \propto\left(h v-E_{g}\right),
$$

where $E_{g}$ is optical band gap between conduction band $\left(E_{C}\right)$ and valence band $\left(E_{V}\right)$. For obtaining this band gap, the absorption spectrum is re-plotted in the format of $(\alpha h v)^{2}$ versus $h v$ (Fig. 2(b)). It is seen that the absorption over the high excitation energy range can be well described by Eq. (2). The band gap for the $a-\mathrm{SiC}$ is then estimated by extrapolation (dashed lines in Fig. 2(b)) to be $3.25 \mathrm{eV}$ (Table I). Previous studies revealed that depending on their compositions and processing conditions, the optical absorption gaps for amorphous silicon oxide and silicon carbide are $8 \mathrm{eV}$ (Ref. 18) and $2.4-3 \mathrm{eV},{ }^{19}$ respectively. The obtained band gap of the $\mathrm{SiC}$, which consisted of mixed $\mathrm{SiC}_{\mathrm{x}} \mathrm{O}_{4-\mathrm{x}}$ tetrahedra, is within the ranges.

Figs. 2(a) and 2(b) suggest that besides the transition between the two extended bands, other absorption mechanisms should also exist since the absorption coefficient is not zero over lower phonon energy range. Previous studies suggested that a so-called Tauc absorption should occur for amorphous semiconductors at a lower excitation energy range by the following equation: ${ }^{20-22}$

$$
\alpha h v=B\left(h v-E_{T}\right)^{n},
$$

where $n$ is a constant, $E_{T}$ is an energy gap (named Tauc band-gap), and $B$ is a constant. According to Inkson, ${ }^{23}$ Tauc absorption is resulted from a transition between deep impurity trap and delocalized band (either conductive or valence band). Pfost et al. suggested that Tauc band-gap can be related to the electronic structures of amorphous semiconductors when $n \sim 1.5,{ }^{22}$

$$
E_{T}=E_{C}-E_{D}
$$

where $E_{D}$ is a deep defect level with a high density of state. In order to test if there is Tauc transition in our material, the absorption spectrum in the excitation energy range of $0.8-1.5 \mathrm{eV}$ was measured and analyzed using Eq. (3). It is seen that the spectrum within this excitation range can be well fitted by the equation (Fig. 2(c)). The $n$ value obtained by curve fitting is very close to 1.5 (Table I), suggesting that the absorption of the $a-\mathrm{SiC}$ over the lower excitation energy range is indeed due to the transition between deep defect states and mobility edge.

By using above information, the electronic structure of the $a-\mathrm{SiC}$ is deduced by assuming valance band $E_{V}=0 \mathrm{eV}$, as shown schematically in Fig. 3. The structure reveals several interesting things. First, the position of the defect level $\left(E_{D}\right)$ suggests that the material is an $n$-type semiconductor and should contain a large amount of defects having electron, instead of holes. It is likely that the defect within the $a$-SiC is associated with carbon dangling bands which have unpaired electrons. Previous study revealed that amorphous
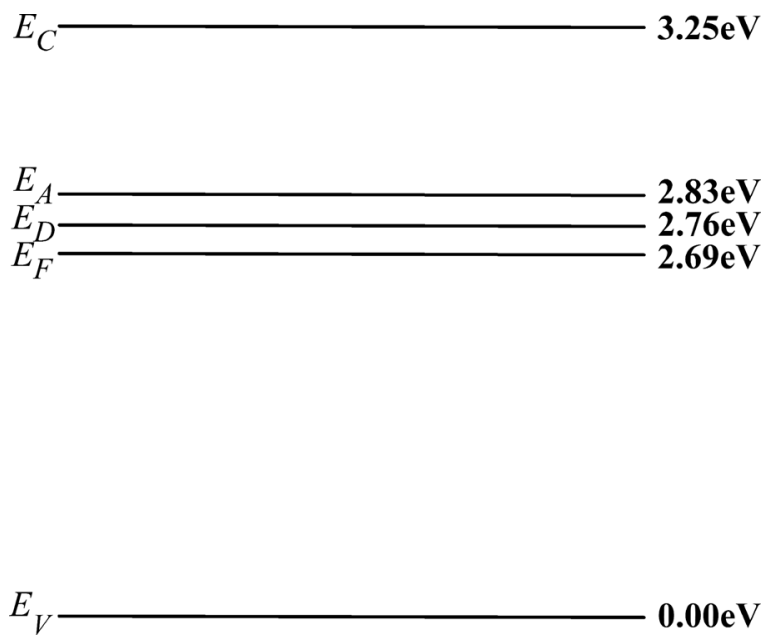

FIG. 3. Schematic showing the electronic structure of the amorphous SiC.

ceramics obtained by thermal decomposition of polymeric precursors indeed contained a large amount of C-dangling bonds within its Si-containing area. ${ }^{24}$ The figure also shows that the band-tail band $\left(E_{C}-E_{A}\right)$ of the material is quite wide. The existence of the band tail is due to the disorder nature of amorphous semiconductors; thereby, the wider band-tail band suggests the higher degree of disorder. This is likely due to the unique processing of PDCs, where the thermal decomposition of precursors occurred at relatively lower temperatures (in our case it is $1000^{\circ} \mathrm{C}$ ). At such low temperatures, the atoms within the covalent bond materials have very slow moving rate, so that the rearrangement for increasing the degree of order in the materials unlikely happened. Another interesting thing can be seen from Fig. 3 is the edge of the band tail is very close to the Fermi level $\left(E_{A}-\right.$ $E_{F}=0.14 \mathrm{eV}$ ). This is likely due to the combining effect of highly disordered structure and high defect concentration. This phenomenon can explain our previous observation that the low-temperature conduction of PDCs is due to band-tail hopping, instead of variable range hopping. ${ }^{5}$ Due to the much higher state density within the band tail, the probability of electrons around Fermi level hoping via the band tail could be much higher than within Fermi level.

In summary, temperature-dependent conductivity and room-temperature optical absorption were measured for the carbon-rich amorphous silicon carbide derived from a polycarbosilane. The results were analyzed using theoretical models to deduce the electronic structure of the material. The obtained electronic structure shows a few unique features, including high defect energy level, wide band-tail band, and overlap between the band-tail band and the defect level. These features are related to the unusual microstructure of PDCs, which is highly disordered and contains a large amount of C-dangling bonds. The overlap between the bandtail band and the defect level, as well as the narrow gap between the band-tail edge and Fermi level, explained the phenomenon that the conduction of PDCs follows band tail hopping, instead of variable range hopping, at low temperatures.

This work was financially supported by the Chinese Natural Science Foundation (Grant Nos. 51372202 and 
51221001), State Key Laboratory of Solidification Processing (Grant No. 82-TZ-2013), and the "111" project (B08040).

${ }^{1}$ L. Liew, W. Zhang, L. An, S. Shah, R. Lou, Y. Liu, T. Cross, K. Anseth, V. Bright, and R. Raj, Am. Ceram. Soc. Bull. 80(5), 25 (2001).

${ }^{2}$ Y. Liu, L. Liew, R. Lou, L. An, V. M. Bright, M. L. Dunn, J. W. Daily, and R. Raj, Sens. Actuators, A 95(2-3), 143 (2002).

${ }^{3}$ Y. Li, Y. Yu, H. San, Y. Wang, and L. An, Appl. Phys. Lett. 103, 163505 (2013).

${ }^{4}$ H. Duan, C. Li, W. Yang, B. Lojewski, L. An, and W. Deng, J. Microelectromech. Syst. 22(1), 1 (2013).

${ }^{5}$ Y. Wang, T. Jiang, L. Zhang, and L. An, J. Am. Ceram. Soc. 92(7), 1603 (2009).

${ }^{6}$ H. Y. Ryu, Q. Wang, and R. Raj, J. Am. Ceram. Soc. 93(6), 1668 (2010).

${ }^{7}$ L. Zhang, Y. Wang, Y. Wei, W. Xu, D. Fang, L. Zhai, K. Lin, and L. An, J. Am. Ceram. Soc. 91(4), 1346 (2008).

${ }^{8}$ P. A. Ramakrishnan, Y. T. Wang, D. Balzar, L. An, C. Haluschka, R. Riedel, and A. Herman, Appl. Phys. Lett. 78(20), 3076 (2001).

${ }^{9}$ A. M. Hermann, Y. T. Wang, P. A. Ramakrishnan, D. Balzar, L. An, C. Haluschka, and R. Riedel, J. Am. Ceram. Soc. 84(10), 2260 (2001).

${ }^{10} \mathrm{P}$. Colombo, R. Riedel, G. D. Sorarù, and H.-J. Kleebe, Polymer Derived Ceramics: From Nano-Structure to Applications (DEStech Publications, Lancaster, PA, 2010).
${ }^{11}$ S. Trassl, M. Puchinger, E. Rossler, and G. Ziegler, J. Eur. Ceram. Soc. 23, 781 (2003).

${ }^{12}$ Y. Wang, L. Zhang, W. Xu, T. Jiang, Y. Fan, D. Jiang, and L. An, J. Am. Ceram. Soc. 91(12), 3971 (2008).

${ }^{13}$ K. Wang, B. Ma, Y. Wang, and L. An, J. Am. Ceram. Soc. 96(5), 1363 (2013).

${ }^{14}$ X. Shi, H. Fu, J. R. Shi, L. K. Cheah, B. K. Tay, and P. Hui, J. Phys.: Condens. Matter 10, 9293 (1998).

${ }^{15}$ M. Schwoerer-Böhning and A. T. Macrander, J. Phys. Chem. Solids 61(3), 485 (2000).

${ }^{16}$ M. Havel, D. Baron, L. Mazerolles, and P. Colomban, Appl. Spectrosc. 61(8), 855 (2007).

${ }^{17}$ P. M. Schneider and W. B. Fowler, Phys. Rev. Lett. 36, 425 (1976).

${ }^{18}$ I. P. Kaminow, B. G. Bagley, and C. G. Olson, Appl. Phys. Lett. 32(2), 98 (1978).

${ }^{19}$ J. B. Casady and R. W. Johnson, Solid State Electron. 39(10), 1409 (1996).

${ }^{20}$ J. Tauc, in Optical Properties of Solids, edited by F. Abeles (NorthHolland, Amsterdam, 1971).

${ }^{21}$ P. O'Connor and J. Tauc, Solid State Commun. 36(11), 947 (1980).

${ }^{22}$ D. Pfost, H. Liu, Z. Vardeny, and J. Tauc, Phys. Rev. B 30, 1083 (1984).

${ }^{23}$ J. C. Inkson, J. Phys. C: Solid State Phys. 14, 1093 (1981).

${ }^{24}$ S. I. Andronenko, I. Stiharu, and S. K. Misra, J. Appl. Phys. 99(11), 113907 (2006). 